\section{AKADEMOS \\ Órgano de difusión de la Red Docencia-Investigación}

ISSN: 1995-4743

Vol. $2, n^{\circ} 33$

AKADEMOS es una revista semestral. De amplio espacio editorial, para la publicación de trabajos inéditos de investigación, artículos de análisis, reseñas y opinión, en los distintos tópicos de las ciencias, la tecnología, las artes y la cultura.

\title{
Representaciones sociales en el discurso filmico salvadoreño
}

Claudia Reneé Meyer

Máster en Gestión Estratégica de la Comunicación por la Universidad

Centroamericana José Simeón Cañas, El Salvador; Licenciada en Mercadotecnia por la Universidad Dr. José Matías Delgado, El Salvador; Investigadora Asociada en Industrias Creativas, en el Instituto de Ciencia, Tecnología e Innovación de la Universidad Francisco Gavidia, El Salvador

cmeyer@ufg.edu.sv

\section{Resumen}

Este artículo aporta una primera aproximación al estudio de las narrativas de largometrajes salvadoreños de ficción estrenados en salas de cine en el país; esto con el propósito de identificar, a través del análisis de discurso fílmico, las representaciones sociales de la salvadoreñidad que puedan mostrarse a tra- vés del mismo, escogiendo para ello la película salvadoreña Malacrianza. Persigue describir la manera como en el cine de El Salvador se cuenta el país y de qué formas se cuenta: el cómo desde una industria cultural inmersa en la economía creativa, se puede construir un imaginario de nación; y cómo se ve representado un país en su cine de ficción, ya que en la ficción se construyen historias, a diferencia

1 Una primera versión del estudio fue aceptada y expuesta en el IX Congreso de Pensamiento Humanístico de Centroamérica, el Caribe y México, COFAHCA (septiembre de 2018), organizado por el Consejo de Facultades Humanísticas de Centroamérica y El Caribe. El título de la ponencia fue: Representaciones sociales en contenidos creativos: el largometraje de cine ficción como medio para describir realidades. Aproximación de análisis discursivo de la película salvadoreña Malacrianza. 
de los documentales que reflejan una visión de la realidad. Esto se realizó a través de un estudio cualitativo, haciendo uso de matrices de análisis ad hoc para los discursos fílmicos, integrando valores y elementos de cultura e identidad para identificar los sentidos y significados en la narración.

Palabras clave: Cine ficción, análisis de discurso, película, Malacrianza, El Salvador.

\section{Abstract}

This article provides a first approximation of the study of narratives of salvadoran fiction films premiered in cinemas in the country; this with the purpose of identifying, through the analysis of film discourse, the social representations of the salvadorans that can be shown through it, the first example is Malacrianza a film by Arturo Menéndez, wich tries to describe the way in which El Salvador's cinema tells the tale of the country and in what ways it is counted: the how from a cultural industry immersed in the creative economy, an imaginary of a nation can be constructed; and how a country is represented in its fiction cinema, since fiction builds stories, unlike documentaries that reflect a vision of reality. This was done through a qualitative study, making use of ad hoc analysis matrices for film discourses, integrating values and elements of culture and identity to identify the senses and meanings in the narrative.

Keywords: Film fiction, discourse analysis, film, Malacrianza, El Salvador.

\section{Introducción}

Que las narrativas del entretenimiento son mainstream cuando se dirigen a una gran audiencia, no descarta que en la construcción de su contenido e hilos se vinculen valores y visiones de mundo. Si a través del entretenimiento se cuentan historias y modos de vida, son entonces un mecanismo idóneo para que, a propósito o sin proponérselo, espacios geográficos cuenten y definan desde ahí, según Martel (2011), su propia "geopolítica de la cultura". En lo denominado por Martel (2011) como "nueva cartografía de los intercambios culturales", el contar la nación pende de pensar la nación, y antes que pensar la nación el tema de la identidad.

Si la construcción colectiva de la identidad pasa por considerarla como no innata, histórica, mudable y siendo una amalgama de pertenencias, ¿cómo se ve inmerso todo ello en una estructura de contenido para el entretenimiento? La estructura identitaria encuentra un paralelismo en la narrativa: de los cuatro términos que considerar en el tema de las identidades (articulación, tensión, contradicción y antagonismo) presenta una semejanza con la estructura narrativa aristotélica en la que todo tiene un inicio, un nudo y un desenlace, en el que se necesita de antagonistas para que existan las contradicciones y la tensión (el conflicto).

Si como dice Rincón (2006) "Los medios de comunicación han construido sus propias culturas o modos de significar, vincular y ritualizar el mundo de la vida” (p. 13), desconocemos a la fecha lo que comunica- 
cionalmente media como símbolos, significaciones, resistencias, reconocimientos, interpretaciones o qué se intercambia, a partir del cine de ficción nacional destinado al entretenimiento; ¿qué nos dice de la realidad cultural y social? De qué forma entonces estará el cine ficción salvadoreño según Rincón (2006) construyendo rituales, expresiones, significando nuevos modos sociales (p.18) ... ¿lo está haciendo?... Si somos los relatos que producimos de nosotros mismos como sujetos y como culturas (p. 87), ¿qué tipo de relato somos y con qué características?

EcuRed define largometraje como "Nombre que recibe aquella producción cinematográfica que tiene un tiempo de duración mayor o igual a sesenta (60) minutos, así como la que teniendo una duración superior a cuarenta y cinco (45) minutos sea producida en soporte de formato $70 \mathrm{~mm}$ con un mínimo de 8 perforaciones por imagen" (https:// www.ecured.cu/Largometraje). Con el ad- venimiento de las nuevas tecnologías, los formatos en cinta y perforaciones han dado paso a lo digital, considerando entonces solo el criterio del tiempo para la definición del metraje de una producción audiovisual.

Los largometrajes son los que cuentan con mayor cabida en distribución y/o exhibición en circuitos de salas de cine comerciales; los corto y medio metrajes rara vez tienen ese tipo de exposición. Luego, retomando aspectos literarios, el cuento es un relato corto que desarrolla una acción concreta a través de pocos personajes y la novela es una extensión larga que desarrolla múltiples acciones que derivan en un hilo principal a través de variados personajes; el quid sigue siendo la extensión: un largometraje encuentra sintonía en las dimensiones narrativas de la novela, pudiendo explayarse en situaciones y personajes, teniendo sin embargo sus propias cotas de desarrollo como puede verse en la siguiente figura: 
Figura No. 1: La creación del guión

\section{ESTRUCTURA INTERNA}

\begin{tabular}{|c|c|c|c|c|c|}
\hline \multicolumn{2}{|c|}{$\begin{array}{c}\text { ACTO } 1 \\
\text { PLANTEAMIENTO }\end{array}$} & \multicolumn{2}{|c|}{$\begin{array}{l}\text { ACTO } 1 \\
\text { NUDO }\end{array}$} & \multicolumn{2}{|c|}{$\begin{array}{c}\text { ACTO } 1 \\
\text { DESENLACE }\end{array}$} \\
\hline \multicolumn{2}{|c|}{$\begin{array}{l}\text { Planteamiento de la } \\
\text { cuestión central }\end{array}$} & \multicolumn{2}{|c|}{ Desarrollo del conflicto } & \multicolumn{2}{|c|}{ Desarrollo acelerado } \\
\hline & \multicolumn{4}{|c|}{$\begin{array}{l}\text { TRAMA PRINCIPAL (remite a la historia) } \\
\text { TRAMAS SECUNDARIAS (remite al tema) }\end{array}$} & \multirow{2}{*}{ RESOLUCIÓN } \\
\hline APERTURA & \multicolumn{2}{|c|}{ Primer punto de giro } & \multicolumn{2}{|c|}{ Segundo punto de giro } & \\
\hline $\begin{array}{c}\text { 崖克 } \\
\text { - de acción } \\
\text { - de diálogo } \\
\text { - de situación }\end{array}$ & \multicolumn{2}{|c|}{$\begin{array}{l}\text { - Cambia el curso de la } \\
\text { historia } \\
\text { - Plantea la cuestión } \\
\text { central } \\
\text { - Compromete al } \\
\text { protagonista } \\
\text { - Eleva el riesgo } \\
\text { - Empuja la historia } \\
\text { al acto } 2 \\
\text { - Introduce un nuevo } \\
\text { escenario }\end{array}$} & \multicolumn{2}{|c|}{$\begin{array}{l}\text { - Acelera la acción } \\
\text { - Cambia el curso de la } \\
\text { historia } \\
\text { - Plantea la cuestión } \\
\text { central } \\
\text { - Compromete al } \\
\text { protagonista } \\
\text { - Eleva el riesgo } \\
\text { - Empuja la historia } \\
\text { al acto } 3 \\
\text { - Introduce un nuevo } \\
\text { escenario }\end{array}$} & $\sum^{\stackrel{x}{U}}$ \\
\hline 30 minutos & \multicolumn{4}{|c|}{60 minutos } & minutos \\
\hline
\end{tabular}

Fuente: $h t t p: / / f i c u s . p n t i c . m e c . e s$

El desarrollo de los tres actos es un escenario temporal de 120 minutos, implica el tiempo requerido para la construcción narrativa idónea de los mismos, que propicia mayores posibilidades de recrear/mostrar elementos de la cultura e identidad locales.

Luego el sitio Definición recoge que ficción es “... toda obra literaria o trabajo cine- matográfico que narra hechos imaginarios (descriptos como ficticios). Por eso, por ejemplo, puede hablarse de libro o película de ficción" (https://definicion.de/ficcion/)

La ficción permite recrear visiones particulares de mundo, visiones que pueden convertirse en representaciones sociales, mien- 
tras que los documentales buscan reflejar un aspecto de la realidad.

Sobre el tema de la producción audiovisual en El Salvador, El diario de hoy reporta que "Durante los años 70, el país llegó a tener más de 85 salas de cine, unas 50 solo en la capital." "2 La misma publicación señala que "Según el historiador Héctor Sermeño, en 1922 se construyó la primera sala de cine como tal y fue bautizada como Cine Mundial. Allí se estrenó, en 1927, 'Águilas Civilizadas', la película salvadoreña más importante de la etapa muda" (http://www. elsalvador.com/noticias/nacional/121135/ salas-de-cine-lo-que-el-tiempo-se-llevo-2/)

Luego el contenido que se exhibe y distribuye, al respecto de la producción cinematográfica nacional en largometrajes de ficción, el investigador Héctor Ismael Sermeño señala que:

... al menos cinco largometrajes de ficción se estrenaron después de 1969 (...): 1) Sexo para dioses $^{3}$, de Otmaro Luna Figueroa, 1985; 2) Nacidos para triunfar, de Javier Durán, 1994, estrenada en nueve salas de las grandes que todavía existían y un gran éxito de taquilla; 3) Sobreviviendo Guazapa, de Roberto Dávila, 2008, presentada en al menos siete festivales internacionales, incluyendo la Berlinale. (...); 4) El libro supremo, de Roberto Dávila,
2013, producida por el salvadoreño estadounidense Carlos Bojórquez. Posteriormente en 2014, se estrenó La rebúsqueda, producida por Clark Films y dirigida por Álvaro Martínez.

(http://www.contracultura.com.sv/ malacrianza-la-enesima-primera-peliculasalvadorena)

En 2015 se estrenó en salas nacionales Malacrianza; a inicios de 2017 Matlat y en 2018 La palabra de Pablo.

De forma intermitente, se han tenido así de 2008 a 2018, cinco producciones estrenadas en el país (Sobreviviendo Guazapa, La rebúsqueda, Malacrianza, Matlat, La palabra de Pablo); producciones que nos están contando cosas mucho más allá del entretenimiento que proporcionan. Una década de producción escasa si se compara con las películas nacionales estrenadas solo en 2016, según la Entidad de gestión de derechos de los productores audiovisuales (2017), por ejemplo en la región centroamericana Costa Rica (3 películas) y Honduras (siete películas), versus los 199 estrenos nacionales reportados en Argentina (p. 38)

Considerando lo anterior, ¿cuál sería el conjunto de producciones salvadoreñas que a la fecha son largometrajes, además ficciones, y luego exhibidos en salas de cine? Las fuentes consultadas arrojan los siguientes:

2 Pasando del tema de exhibición al de distribución, de todo ese circuito tenemos a 2018 tres cadenas exhibidoras en el país: Cinépolis, Cinemark y Multicinemas, que en sus pantallas ofertan en su mayoría cine estadounidense, teniendo esporádicamente ciclos de cine alternativo y aún de forma más eventual producciones salvadoreñas.

3 Promocionada como el primer largometraje pornográfico realizado en El Salvador. 


\section{Tabla No. 1: Largometrajes ficción salvadoreños}

\begin{tabular}{l|l|l|l}
\multicolumn{1}{c}{ Película } & \multicolumn{1}{c}{ Director } & \multicolumn{1}{c}{ Duración } \\
producción
\end{tabular}

Fuente: Elaboración propia con base a estudios de Durán, Marroquín y Olmedo (2012); Baldovinos y Larkin (2013); y con base a notas periodísticas.

Con base a lo anterior, se visualiza que al 2018 existen 10 largometrajes ficción producidos en el país, en los 47 años que comprende el periodo de producción de todas estas películas (en promedio una película cada cuatro años y medio). Ello muestra que la producción de este tipo de productos del entretenimiento no es grande en volumen y, para efectos de la historia cinematográfica salvadoreña, este número es mínimo en comparación a otros países ${ }^{6}$.

Sobre este escenario de producción audiovisual, se colige que la producción de largo- metrajes de ficción es esporádica. Luego, a partir de la revisión bibliográfica, se constata que el estudio de la filmografía salvadoreña se ha referido a la fecha a sus condiciones de producción, problemas, retos y cronología; se carece de abordajes acerca de las prácticas sociales salvadoreñas -desde lo cultural e identitario-, de lo que se ve en lo fílmico: no se han estudiado los relatos, se desconocen las visiones, los valores y representaciones que comunican. Esto sumado a que en las reseñas o publicaciones periódicas sobre películas concretas, se escribe mezclando lo narrativo de la misma con los valores de

4 Considerada el primer largometraje realizado en El Salvador (https://historico.elsalvador.com/211430/5-peliculas-que-muestran-el-salvadorde-antano.html)

5 La película fue estrenada en Cinépolis en 2018.

6 Por ejemplo en Guatemala tiene un ritmo de producción de un largometraje ficción por año. 
producción técnica de las películas, pero no estudios a profundidad desde lo discursivo. Por ello es inviable al momento constatar que el cine salvadoreño haya desempeñado un papel significativo como mediador de identificación nacional o qué signos de reconocimiento e identidad se construyen en esas narrativas fílmicas a la fecha.

\section{Método}

El abordar una realidad investigada desde el lenguaje utilizado, permite acercarse al mundo de las representaciones sociales, ya que, según Núñez (2004), “... los contextos de producción y recepción del enunciado lingüístico, y los propósitos de los interlocutores, son los que, analizados minuciosamente, pueden dar explicaciones acerca de la naturaleza de las prácticas sociales de un determinado grupo humano".

El cine es una categoría discursiva, con significados que a través de los años pueden permanecer, mutar o resistirse; discursos que como los periodísticos, televisivos o radiales, deben ser examinados como espejos de lo que socialmente acontece como práctica. Si el concepto de nación es una representación (más allá de lo territorial), el cine es contar en imágenes una suma de representaciones en relato. Por ello en los relatos fílmicos debiera ser posible investigar cuáles han sido o cómo se cuenta lo nacional o la identidad desde la ficción.

Esto pasa por considerar el cine como un medio que nos permite entonces relacionarnos de otra forma con nuestra historia. En este artículo se realiza un primer examen de la construcción, difusión y recreación de la identidad salvadoreña a partir de las narrativas de productos creativos destinados al entretenimiento: La representación que se hace del propio país, qué o cuáles son los elementos recurrentes, cómo se construye la nación en su propio cine y a través de qué tipo de representaciones.

Para ello se identificó, a través del análisis de discurso fílmico, los elementos identitarios conductuales, de lenguaje, costumbres e históricos reflejado en el largometraje de ficción salvadoreño Malacrianza.

El abordaje realizado ha sido de carácter cualitativo (exploratorio/descriptivo) de tipo comunicológico discursivo, estudiando elementos culturales e identitarios a partir de las narrativas cinematográficas de ficción; este acercamiento se debe a que el objeto de estudio parte por describirse y explicarse, más que numerarse o cuantificarse.

\section{II.1 Marco teórico referencial}

Es importante considerar en este apartado, aspectos generales como:

- Las narrativas mediáticas como elemento base de abordaje se refieren al tipo de construcción narrativa según los medios de comunicación, estructuras que determinan, de acuerdo a las posibilidades de producción de los medios, las formas y usos de estas construcciones.

- Luego en particular las narrativas cinematográficas, vistas estas desde su cons- 
trucción como lenguaje especializado para contar historias (elementos técnicos), pautas para su análisis desde lo sociológico, la estética, la antropología, lo semántico y lo semiótico.

- La cultura, identidad y representaciones sociales.

- El cómo abordar la narrativa cinematográfica a fin de dilucidar las representaciones sociales, parte por aproximarse a las metodologías de análisis discursivo cinematográfico.

- Casos prácticos de análisis discursivo cinematográfico: la búsqueda de evidencias de trabajos iguales o parecidos en otras latitudes; encontrando qué si bien hay abordajes a partir de representaciones sociales, éstas se especifican y se escoge la perspectiva de estudio (género, migraciones, indígenas, entre otros), resultando así en investigaciones monotemáticas de una representación social concreta y en corpus mucho más amplios de cinematografías nacionales.

Uno de los principales exponentes de actualidad sobre las narrativas mediáticas es Omar Rincón, quien en el libro Narrativas mediáticas o cómo se cuenta la sociedad del entretenimiento (2006), hace un recorrido de lo cultural a lo mediático, pasando por las estéticas y los tipos de narración mediática. Sobre el cine en particular, Rincón (2006), menciona “... ser el modo audiovisual más antiguo y estructurado en cuanto a su contenido, a su lenguaje, a sus texturas, a sus movimientos de cámara, a su iluminación, a su sonido" (p. 205). Además, refiere según Ricoueur (2000) que "No hay narración que no esté mediatizada por signos, símbolos y textos" (p. 97). Por esta vía, refiere Rincón (2006) que "La narración es un proceso por el que una obra audiovisual sugiere a un espectador los pasos que lo conducen a completar una historia, a comprender lo contado, no lo que se quiso decir" (p. 97) Luego lo mediático es derivado a lo que media, lo que comunica, y al respecto el mismo Rincón (2006) señala que "El potencial de acción simbólica de los medios de comunicación está en la competencia que tiene para producir vínculo y conexión entre los seres humanos, para imaginar relatos en los que quepamos todos" (p. 99). Es así como el cine, en todo su aparataje técnico y narrativo, articula y media historias.

Según Gardies (1995), citado por Pulecio Mariño (2008), "El relato cinematográfico no es un relato puesto en imágenes y sonidos, sino que son las imágenes y sonidos articulados de tal forma que producen el relato"; relato que es construido entonces a partir de un lenguaje. Sobre el lenguaje cinematográfico, Pulecio Mariño (2008) nos dice que:

Cuando vemos y comprendemos una película, este acto se basa en el reconocimiento de un cierto número de elementos que, articulados de una determinada manera, constituyen lo que llamamos aquí lenguaje cinematográfico. Es un lenguaje, no solo por la forma en que estructura su narratividad, sino porque tiene el poder de comunicar un sentido. (p. 167)

Partiendo de la definición de Gardies y de Pulecio Mariño, lo fílmico tiene entonces 
varias vertientes de abordaje desde lo discursivo ya que hablamos de relatos y de lenguaje; cada elemento inmerso puede ser sujeto de estudio desde lo narrativo y ser narrativa misma: la luz, los fondos, los diálogos, el tipo de montaje, la estructura narrativa total, los encuadres ${ }^{7}$. Espinoza y Martínez (2017), proponen un "modelo dialógico simétrico/asimétrico", basado en el diseño de García y Finol (2006), el cuál parte por considerar el cine como comunicación de masas, luego la introducción de tópicos u ejes temáticos que permitirían encontrar u clasificar el discurso de forma genérica según la construcción total del relato; y por último la integración de forma y contenido. Esta propuesta de análisis se cristaliza en la tabla siguiente:

Tabla No. 2: El modelo dialógico simétrico/asimétrico.

\begin{tabular}{|c|c|c|}
\hline \multicolumn{3}{|c|}{$\begin{array}{l}\text { Fragmentos filmicos / Actividades situadas } \\
\text { El orden de lo pragmático }\end{array}$} \\
\hline \multicolumn{2}{|c|}{ El orden de los sintagmático } & El orden de lo paradigmático \\
\hline $\begin{array}{l}\text { Operadores sintácticos } \\
\text { Escena-Diálogo }\end{array}$ & $\begin{array}{l}\text { Operadores formales } \\
\text { técnico-expresivos }\end{array}$ & Operadores semánticos \\
\hline $\begin{array}{l}\text { Descripción de la escena, caracte- } \\
\text { rísticas de los objetos, el tiempo, } \\
\text { diálogo, adaptación del diálogo, } \\
\text { tipo de diálogo, ruidos, música, de- } \\
\text { sarrollo de la música. }\end{array}$ & $\begin{array}{l}\text { Encuadres, composición, pla- } \\
\text { nos, contraplanos, movimien- } \\
\text { tos de cámara, angulaciones, } \\
\text { punto de vista, ritmo, ilumi- } \\
\text { nación, escenografía. }\end{array}$ & $\begin{array}{l}\text { Sentido sugerido, relación interior/ } \\
\text { exterior en las actividades, actores so- } \\
\text { ciales, roles temáticos, categorías se- } \\
\text { mióticas mensajes e isotopías, valores, } \\
\text { discursos sociales, el saber y el parecer. }\end{array}$ \\
\hline
\end{tabular}

Fuente: Espinoza y Martínez (2017), p. 4

Luego Zavala (2010), nos menciona que el "análisis formal" de una película, se refiere a su "interpretación" y persigue como objetivo el "reconocer los componentes del lenguaje cinematográfico que permiten distinguir una película de otra (y su significación) $=$ imagen, sonido, montaje, puesta en escena y narración”, es decir, "precisar la naturaleza estética y semiótica de la película”. Para ello enuncia dos tipos de análisis:

“a) Análisis estético: Interés por el espectador implícito y su experiencia estética (aproximaciones transdisciplinarias) b) Análisis semiótico: Interés por el enunciado y sus condiciones de

7 Pulecio Mariño (2008), señala que "el lenguaje cinematográfico se construye a partir de la articulación de los siguientes elementos y procedimientos: planos -encuadre, ángulos de toma, movimientos de la cámara-, elipsis, profundidad de campo, imagen, iluminación, montaje, enlaces y transiciones, metáforas y símbolos, sonido -diálogos, música y efectos-." (p. 168) 
enunciación (aproximaciones estructuralistas, formalistas, intertextuales, estudios de traducción lingüística y semiótica, etc.)" (p. 25)

Por otra parte, Pulecio Mariño (2008) parte por desglosar los tópicos inmersos en "el relato y el cine" a partir de los abordajes de los teóricos Barthes (lo estructural del relato), Propp (lo morfológico del cuento), Bremond (alcances y definiciones) y Greimas (lo semántico de los relatos y el modelo actancial).

$\mathrm{Al}$ referirse eminentemente a lo narrativo, Pulecio Mariño (2008) afirma que:

Todo relato está compuesto de dos grandes dimensiones, que aunque inseparables, por razones de metodología se las presenta bajo sus particulares denomi- naciones. Una es la correspondiente a la instancia de lo que se ha llamado el contenido y a la otra la forma. A partir de los enunciados de las teorías estructuralistas, estas denominaciones comunes y de enunciado muy remoto en la historia de las expresiones humanas, adquirieron una redefinición a partir de la cual se amplió su sentido. Así el estructuralismo enseña que en toda narración se distinguen dos niveles: La historia y el discurso. (p. 94).

Siendo en lo anterior la historia la cadena de sucesos y el discurso el cómo se expresa esa cadena de sucesos.

Para el análisis estructural del relato, y con base a los elementos mencionados por diferentes teóricos, Pulecio Mariño (2008) propone el siguiente modelo integrado:

\section{Figura No. 2: Modelo integrado de análisis estructural del relato.}

\begin{tabular}{|c|c|c|c|c|c|}
\hline $\begin{array}{l}\text { HISTORIA } \\
\text { Plano de ¿Qué? } \\
\text { Invención (Argumenta) }\end{array}$ & LOGICA DE LAS ACCIONES & \multicolumn{2}{|c|}{$\begin{array}{l}\text { FUNCIONES } \\
\text { Unidades narrativas mínimas. } \\
\text { Definen y articulan una co- rela- } \\
\text { cón. Es el "germen" de una serie de } \\
\text { acciones. } \\
\text { Es lo que "dicer," no la forma en que } \\
\text { lo dice. }\end{array}$} & $\begin{array}{l}\text { DISTRIBUTIVAS } \\
\text { FUNCIONES } \\
\text { PROPP/BREMOND } \\
\text { "HACER" } \\
\text { INTEGRATINAS } \\
\text { INDICOOS } \\
\text {-CARACTER } \\
\text { - IDENTIDAD } \\
\text {-ATMOSFERA } \\
\text { - NONEA PSICOLOGICA } \\
\text {-"DESCIFPAMIENTO" } \\
\text { "SER" }\end{array}$ & 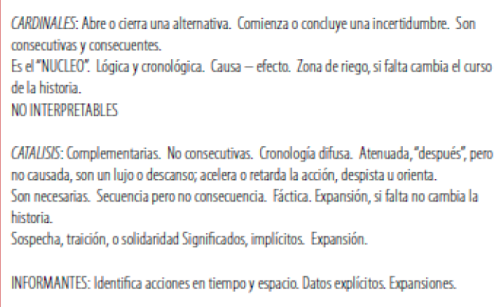 \\
\hline $\begin{array}{l}\text { DISCURSO } \\
\text { Plano de la expresión } \\
\text { TIEMPO, MODO Y ASPECTOS } \\
\text { DEL RELATO }\end{array}$ & $\begin{array}{l}\text { SINTASIS DE LOS PERSONA } \\
\text { ENUNCIADOR, } \\
\text { NARRACION ENUNIADO } \\
\text { DESTINATARIO } \\
\text { SISTEMA DEL RELATO }\end{array}$ & OR, NARRADOR & \multicolumn{3}{|c|}{ 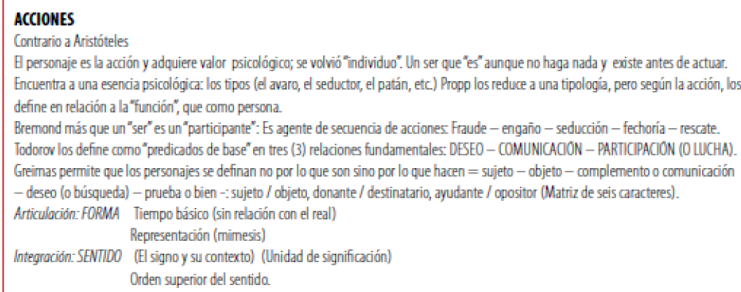 } \\
\hline
\end{tabular}

Fuente: Pulecio Mariño (2008), p.98 
Sobre ello, Bordwell, citado por Pulecio Mariño (2008), hace mención que la narración de una historia de estilo cinematográfico tiene tres aspectos a considerar: es una representación (conlleva significados), es una estructura (es un todo y tiene sus partes) y es un proceso (el cómo, el qué, los por qué de las acciones de los personajes, cómo se suceden las cosas, cuál es la intención sobre el receptor)

Retomemos a Zavala (2010) cuando hablaba del análisis estético. Al respecto Pulecio Mariño (2008), sobre la estructura de una película señala que:

Se puede hablar a partir de la enunciación y análisis de los planos, o las formas de su continuidad en el montaje. También puede explorarse la construcción de las escenas y de las secuencias o, también, aludir a otras las grandes articulaciones del relato. Sobre estas grandes unidades suele hacerse intervenir elementos heterogéneos del análisis. (p. 116)

Siendo estos elementos que los encontramos como los "operadores formales técnico-expresivos", del modelo dialógico simétrico/asimétrico visto al inicio. Luego Pulecio Mariño (2008) señala como "significantes cinematográficos a los recursos del lenguaje cinematográfico los cuales varían de acuerdo a la época, al género y al modo como los directores, los utilizan estos para componer sus películas." (p. 167)

A partir de ello, Lukinbeal (2004), referido por Maza (2014), nos hace ver adicional- mente que "la interrelación entre los medios audiovisuales, la producción cultural y la creación de significados ocupa un lugar destacado en la geografía, la teoría y crítica de cine y los estudios culturales" (p. 75). Sitúa de esta forma lo cinematográfico, como medio audiovisual, como una vía articuladora y que puede visibilizar elementos culturales a partir de significaciones. Luego el mismo Lukinbeal (2004) habla así de una "geografía cinematográfica", enfocándose éste abordaje en la incorporación de la "conexión entre cine, representación y espacio geográfico al ámbito específico de la geografía cultural y que concentra su estudio en las representaciones de los espacios geográficos en el cine y la televisión" (p. 79). Esto nos deja planteada una relación entre espacio, realidad y su traslado a la pantalla cinematográfica.

\section{II.2 Categorías y procedimiento}

Al respecto del tratamiento metodológico, es crucial la aseveración de Pulecio Mariño (2008), que señala:

"El significado de una película no se encuentra como un tesoro oculto en realidad se construye, y es aquí donde comienzan los problemas: No hay un método universal a través del cual se establezca la fórmula para construir significados, entonces, debemos encontrar al menos sustitutos parciales y particulares. Todo lo que podemos hacer es iniciar un proceso de aprendizaje. Claro está, hay teorías, protocolos y estrategias, así como grados de inferencia. Todo análisis es parcial y personal, aunque coincidan, con él, tantos otros.” (p. 177) 
Esta afirmación es determinante, ya que al buscar el abordaje del análisis del discurso fílmico en términos metodológicos, los autores se decantan por lo que les sea de utilidad acorde a la perspectiva de estudio del objeto definido.

En el propósito de este estudio se encuentran elementos culturales y semióticos referidos al lenguaje cinematográfico, de discurso y relato; al final se propone descubrir cuál es la representación que se hace del propio país, qué o cuáles son los elementos recurrentes, cómo se construye la nación en su propio cine y a través de qué tipo de representaciones son de las que se hace uso para ello; esto en principio a partir de un primer ejercicio realizado con un solo largometraje salvadoreño de ficción. Pareciera que lo anterior deja por fuera los elementos del lenguaje cinematográfico señalados por Pulecio Mariño (2008), y los operadores sintácticos de escena-diálogo y los operadores técnicoexpresivos descritos por Espinoza y Martínez (2017), siendo considerados solamente los operadores semánticos. Sin embargo, no hay que olvidar que Gardies (1995) en Pu- lecio Mariño (2008) asevera que “...son las imágenes y sonidos articulados de tal forma que producen el relato" (p. 104), siendo así que no es viable ni recomendable aislar lo semántico-semiótico de los elementos que construyen ese lenguaje cinematográfico, ya que esta construcción es la que proporciona el sentido que se busca en cuanto a las representaciones.

Si cultura es, según la UNESCO, “el conjunto de los rasgos distintivos, espirituales, materiales y afectivos que caracterizan una sociedad o grupo social. Ella engloba, además de las artes y las letras, los modos de vida, los derechos fundamentales del ser humano, los sistemas de valores, creencias y tradiciones", y si la identidad es, según Molano (2007), “... el sentido de pertenencia a una colectividad, a un sector social, a un grupo específico de referencia" (p. 73), conlleva en su concepción elementos de historicidad y de arraigo.

Dado lo visto en el marco teórico referencial y las valoraciones metodológicas expuestas, las categorías de abordaje de análisis discursivo del estudio fueron: 
Tabla No. 3: Categorías de abordaje del análisis discursivo.

\begin{tabular}{|c|c|c|c|}
\hline \multicolumn{2}{|c|}{$\begin{array}{c}\text { Lenguaje cinematográfico ("significantes } \\
\text { cinematográficos) }\end{array}$} & \multicolumn{2}{|c|}{ Representaciones sociales } \\
\hline $\begin{array}{l}\text { Modelo dialógico } \\
\text { simétrico/asimétrico }\end{array}$ & Narración & Lo cultural & Lo identitario \\
\hline $\begin{array}{l}\text { - Operadores } \\
\text { sintácticos } \\
\text { - Escena-Diálogo } \\
\text { - Operadores } \\
\text { formales técnico- } \\
\text { expresivos } \\
\text { - Operadores } \\
\text { semánticos }\end{array}$ & $\begin{array}{l}\text { - Representación } \\
\text { - Estructura } \\
\text { - Proceso }\end{array}$ & $\begin{array}{l}\text { - Creencias } \\
\text { (religión) } \\
\text { - Valores } \\
\text { - Normas y } \\
\text { sanciones } \\
\text { - Organización } \\
\text { social } \\
\text { - Símbolos } \\
\text { - Vestimenta } \\
\text { - Idioma o } \\
\text { lenguaje } \\
\text { - Lo culinario } \\
\text { - Tecnología }\end{array}$ & $\begin{array}{l}\text { - Historia } \\
\text { Patrimonio cultural material (incluye } \\
\text { lo natural) }{ }^{8} \text { : } \\
\text { a. Los monumentos } \\
\text { b. Los conjuntos } \\
\text { c. Los lugares (patrimonio natural) } \\
\text { d. Bienes culturales muebles } \\
\text { - Patrimonio cultural inmaterial9: } \\
\text { a. Tradiciones y expresiones orales } \\
\text { b. El idioma } \\
\text { c. Patrimonio cultural inmaterial; } \\
\text { d. Artes del espectáculo; } \\
\text { e. Usos sociales, rituales y actos } \\
\text { festivos; } \\
\text { f. Conocimientos y usos relacionados } \\
\text { con la naturaleza y el universo; } \\
\text { g. Técnicas artesanales tradicionales }\end{array}$ \\
\hline
\end{tabular}

Fuente: Fuente: elaboración propia con base a Espinoza y Martínez (2017), p.4, y la UNESCO (1978 y 2003)

El procedimiento realizado consistió en:

1. Establecer la narración de la película en su representación, estructura y proceso

2. De cada uno de los elementos narratológicos, escoger secuencias o cuadros clave conductores de la historia

3. De dichas secuencias o cuadros aplicar el modelo dialógico simétrico / asimétrico

4. Desagregar las representaciones sociales por unidades de análisis, por ejemplo:

8 Según la Convención de 1972 y de la Recomendación sobre la Protección de los Bienes Culturales Muebles de 1978.

9 Según el Convenio Internacional para la Salvaguardia del Patrimonio Cultural Inmaterial. 
Tabla No. 4: Unidades de análisis por representación social.

\begin{tabular}{|c|c|}
\hline Unidad de análisis: Cultura & Valoraciones \\
\hline Lenguaje & $\begin{array}{l}\text { ¿Hace uso de salvadoreñismos la película?, ¿cuáles? } \\
\text { Identificar los elementos denotativos, connotativos, haciendo uso de foto- } \\
\text { gramas (cuadros de la película) } \\
\text { ¿Hay enunciados claramente salvadoreños?, ¿cuáles? } \\
\text { ¿Cómo es el lenguaje empleado y los diálogos? (si es un léxico cerrado, si es } \\
\text { coloquial, si es refinado, si es neutro, si hace uso de muletillas o modismos, } \\
\text { si son diálogos mordaces, pausados, lineales, llenos de doble lecturas, etc.) } \\
\text { ¿Qué se dice, quién lo dice, cómo lo dice? }\end{array}$ \\
\hline Conducta & $\begin{array}{l}\text { ¿Cuáles valores salvadoreños se ven reflejados en la película? } \\
\text { Realizar un juicio de valor sobre las actitudes de los personajes. } \\
\text { ¿Se reflejan clases sociales en la película?, ¿cuáles? }\end{array}$ \\
\hline Costumbres & $\begin{array}{l}\text { ¿Cuáles creencias o tradiciones se ven reflejadas? } \\
\text { ¿Qué escenas típicas salvadoreñas se ven en la película? } \\
\text { ¿Hay costumbres de otras épocas en la película? } \\
\text { ¿Dicen algo acerca de las costumbres los elementos de anuncios, calles u } \\
\text { otros afiches o cosas que salgan en la película? } \\
\text { ¿La música dice algo de la época o de las costumbres? }\end{array}$ \\
\hline
\end{tabular}

Fuente: Elaboración propia.

5. En las secuencias que se haya aplicado el modelo dialógico simétrico / asimétrico, implementar el desagregado de las representaciones sociales (se utilizó un cuadro integrado).

6. Definir qué elementos del lenguaje cinematográfico potencian las representaciones sociales.

7. Determinar la frecuencia de las apariciones de las representaciones sociales, si estas se refuerzan, se muestran o se consolidan.

\section{Sobre la película}

Malacrianza narra la historia de don Cleo, papel interpretado por Salvador Solís, un vendedor de piñatas que es extorsionado con 500 dólares y que debe entregarlos en menos de 72 horas. La película fue exhibida en el AFI Silver Theatre (Washington), el Festival Internacional de Cine de La Habana (Cuba), el Festival Internacional de Cine de
Panamá, entre otros, antes de su proyección en salas salvadoreñas.

Ficha técnica (Con base a data de imdb.com y del portafolio de Latam pictures)

- Nombre: Malacrianza

- Género: Drama

- Duración: $1 \mathrm{hr}$ con 10 min (70 min)

- Dirección y guion: Arturo Menéndez 
- Sinopsis: Malacrianza cuenta la historia de Don Cleo, un humilde vendedor de piñatas en la ciudad de San Salvador, quién un día recibe una nota de extorsión por \$ 500 USD. El personaje debe conseguir el dinero en menos de 72 horas. Al verse obligado y sin recursos para conseguirlo, decide enfrentarse a los extorsionadores que enviaron la nota.

\section{Resultados}

La línea narrativa de Malacrianza cuenta la historia de don Cleo, un hombre de tercera edad que combatió en el conflicto civil como guerrillero, que trabaja de hacer piñatas. Don Cleo vive con su hijo Juan, que llega poco a casa, y quien además consume drogas. La vida de don Cleo cambia cuando un joven se presenta en su trabajo aludiendo que su hijo, producto de una relación de hace años con una mujer en el interior del país. Orlando, que así se llama el joven, quiere de don Cleo que solo le dé donde vivir, mientras él busca trabajo para financiar su sueño que es estudiar para ser pastor; en el ínterin don Cleo cultiva una relación amorosa con una mujer que le lleva diario el almuerzo a su trabajo; por azares de la salud de su madre, Orlando alega que debe regresar con ella, yéndose apurado. El siguiente punto de giro es la extorsión a don Cleo: le piden $\$ 500.00$ a ser entregados en 72 hrs. Esa presión hace que don Cleo busque ayuda entre sus amistades, pudiendo conseguir la mitad con una prestamista, dinero que se lo roba un delincuente. Busca ayuda bancaria, no la obtiene; busca apoyo policial, tampoco. Cansado, vencido, ingresa a una colonia tomada por pandillas, entregándose, dice estar a la disposición porque ya no puede más con el miedo y el dinero no lo tiene así que lo maten. Los pandilleros no son quienes lo han extorsionado, tienen pena por el drama de don Cleo y son ellos quienes le dan todo el dinero para que pague la extorsión. Al pasar los días, don Cleo se acompaña con su enamorada y revisando cosas que dejó Orlando encuentran una suma fuerte de dinero. Se escucha fuera un disparo y un vecino comenta que han asesinado al extorsionista de esa localidad, resultando ser Orlando.

Para el análisis de esta narrativa, por fragmento fílmico vamos a interpretar secuencia. No obstante, para efectos de este estudio, se ha realizado el análisis con base a cuadros concretos de la película (fotogramas). La matriz utilizada fue la siguiente: 
Tabla No. 5: Matriz de análisis utilizada

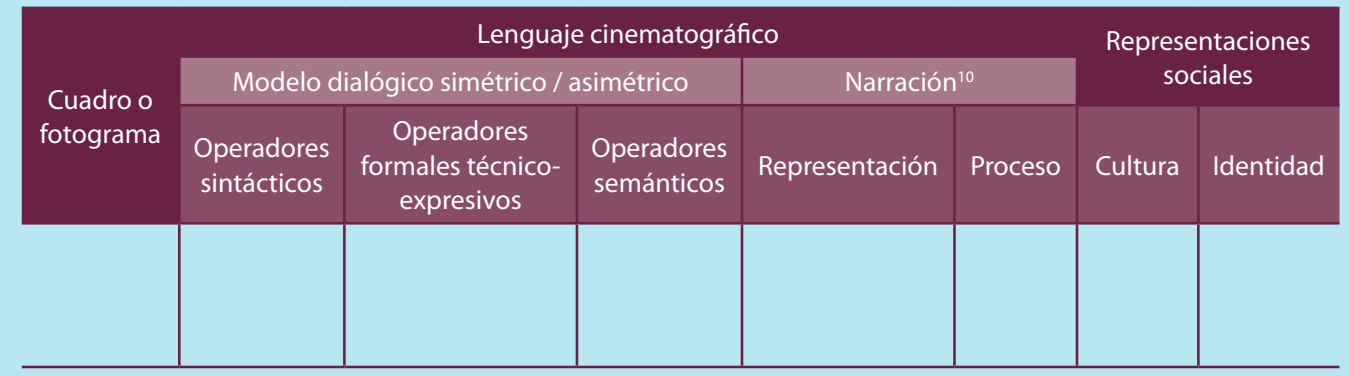

Fuente: elaboración propia con base a Espinoza y Martínez (2017), p.4 y la UNESCO (1978 y 2003)

En atención a lo anterior, se han seleccionado nueve cuadros (fotogramas) específicos del largometraje (tres del inicio, tres del medio y tres del final), sobre la base de los cuáles se presentan los siguientes resultados:

10 En vez de analizar una secuencia se trabajará con cuadros o fotogramas, es decir una imagen fija. Por ello la comuna de estructura dentro del apartado de narración no será utilizada, en vista que la estructura va en pos de analizar secuencias. 


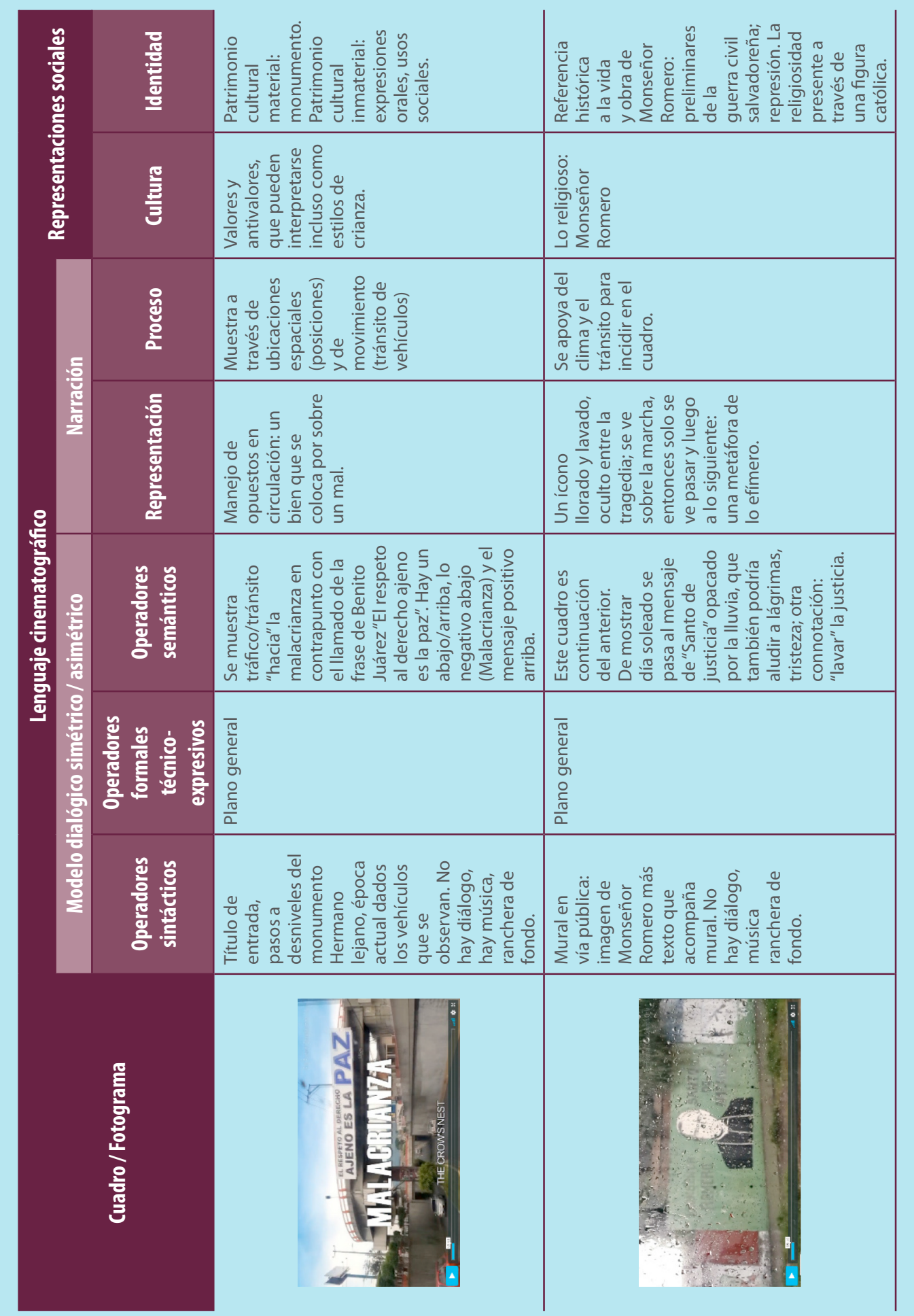


AKADEMOS Julio-Diciembre 2019, n. ${ }^{\circ} 33$, ISSN: 1995-4743

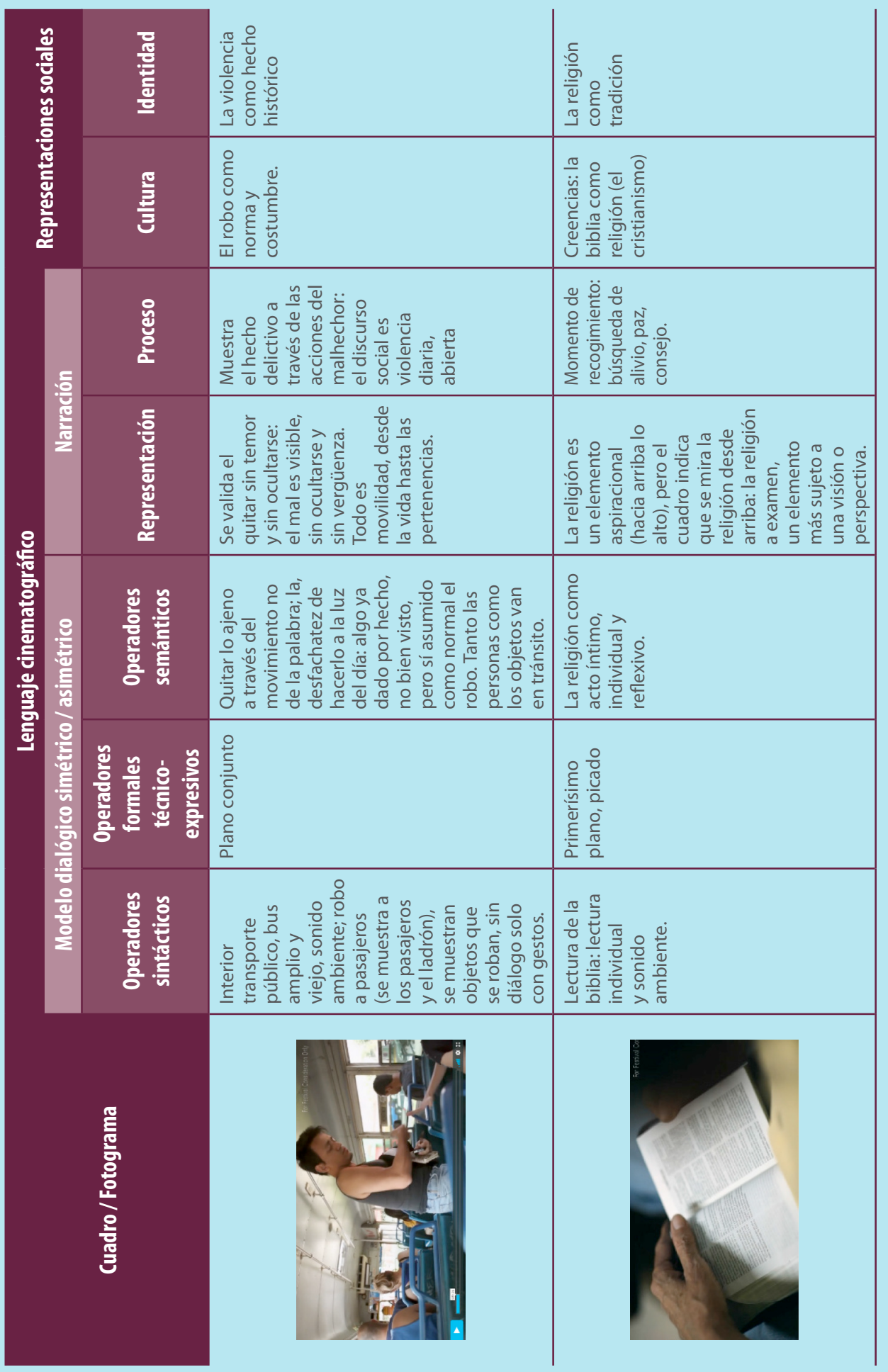




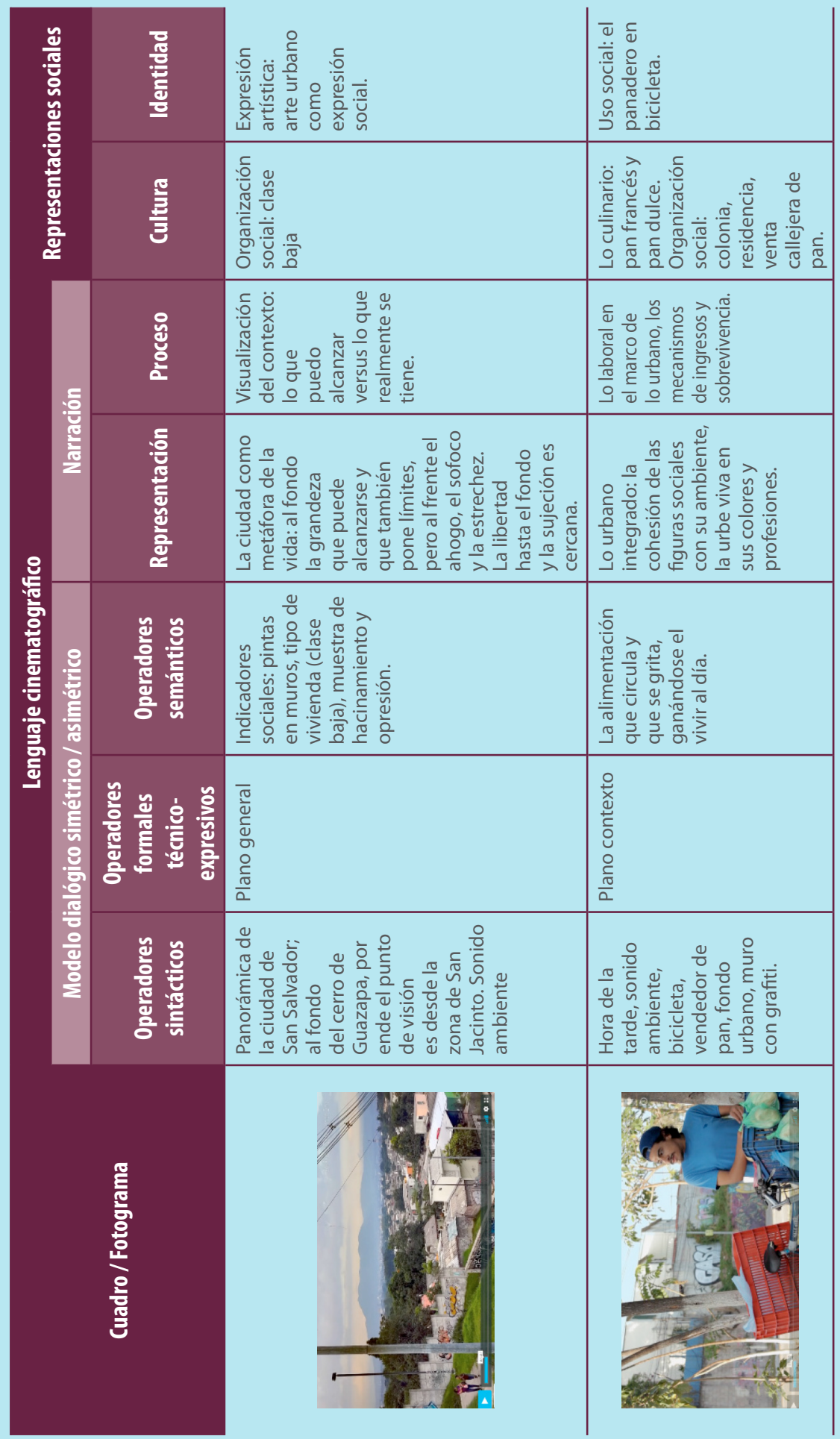




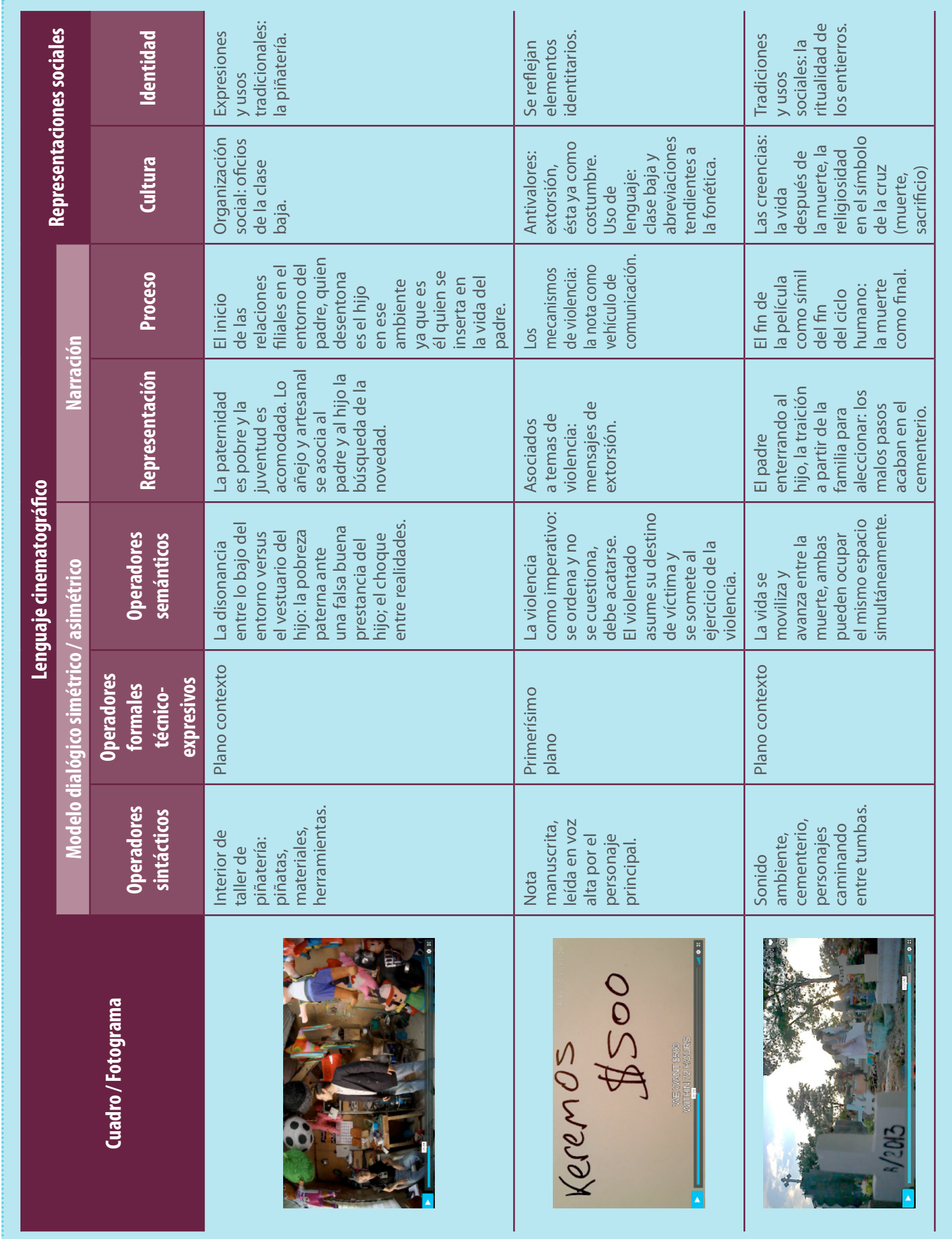




\section{Discusión}

El análisis de resultados nos muestra que:

- Es válido el análisis de piezas fílmicas de ficción, particularmente los largometrajes, como conductos de representaciones sociales nacionales.

- La propuesta híbrida de matriz de análisis integrado es efectiva para los propósitos buscados en el presente estudio.

- Para futuros análisis, el incorporar la columna de estructura a lo narrativo, podrá proveer de mayores elementos de análisis, al facilitar el tratamiento de acción continua (secuencia) por sobre cuadros fijos.

- Sobre elementos de representación a nivel de semiótica puede observarse que:

$\checkmark$ El tránsito: el movimiento es un elemento y estrategia para mostrar en la película, ya sea como un ir y venir entre posturas, objetos, o el mismo tránsito de la vida misma a través de las acciones humanas.

$\checkmark$ Juego de los contrarios u opuestos: hace uso y gala de contrastes en elementos además de antítesis, como el negro versus el blanco, arriba o abajo, muerte o vida, lo lejano a través de lo cercano, etc. Su uso y disposición se convierte en un mecanismo de reflexión y discusión que enriquece la narrativa de la película.

Se verificó la existencia de elementos culturales y de identidad presentes, es decir, una salvadoreñidad presente en el discurso fílmico:
- Culturales:

$\checkmark \quad$ Lo religioso es muy presente como creencia y como práctica.

$\checkmark$ La organización social es altamente visible dentro del discurso fílmico, tanto como contraste como situación concreta.

$\checkmark$ La violencia está presente como antivalor pero a su vez como cotidianeidad asumida como normal.

- Identidad:

$\checkmark$ Hay uso de referencias a patrimonio cultural material.

$\checkmark$ Existe presencia y muestra de manifestaciones artísticas urbanas

$\checkmark$ Lo historicidad del país se refleja en el relato, a través del uso de personajes e íconos.

$\checkmark$ Se reflejan expresiones y usos sociales además de tradiciones.

De ambos elementos los más presentes son la religión y como contrapunto la violencia: ante la agresión y los actos delictivos, el refugio en la fe; esto reforzado a través del fin de la historia: las malas acciones solo pueden llevar a la muerte.

\section{Conclusiones}

Los resultados y discusión de esta primera aproximación al estudio de las representaciones sociales salvadoreñas presentes en un discurso fílmico local, nos llevan a concluir que:

- Es necesario profundizar en el estudio de cuáles son las representaciones sociales nacionales reflejadas en los largometrajes de ficción salvadoreño, abarcando 
un corpus de estudio más amplio, en virtud de haber validado la metodología con esta experiencia.

- Un análisis más amplio llevaría a descubrir cuáles son las representaciones sociales del país que se ven reflejadas en su cine de ficción, en su totalidad.

- Trabajar un corpus más amplio permitiría examinar cuáles son las representaciones sociales recurrentes, permanentes o que mutan, en las narrativas cinematográficas de ficción salvadoreñas.

- Adicionalmente se vislumbra como necesario el abordar a los creadores de las películas, a fin de indagar sobre las mo- tivaciones culturales e identitarias que pudieron haber estado o no presentes (intencionales o no), al momento de la producción; y su contraste con lo encontrado a través del análisis metodológico respectivo.

- Un contrapunto forzoso en este análisis, en el que se está considerando al emisor (generador de la película), el mensaje (el análisis de la película mis$\mathrm{ma}$ ), son las audiencias (los receptores del discurso fílmico; con el propósito de indagar en futuros estudios qué tanto perciben de sí mismos o de la salvadoreñidad en lo visto.

\section{Referencias}

Baldovinos, R.; Larkin, C. (2013). Cine y televisión. Análisis de situación de la expresión artística en El Salvador. Fundación Accesarte. Recuperado de: http://plataformadecultura.com /web/2016/01/26/ cine-y-television-analsis-de-situacion-de- la-expresion-artisticaen-el-salvador/

Contracultura (27 de octubre de 2015). Malacrianza: la enésima primera película salvadoreña. Recuperado de: http://www.contracultura.com.sv/malacrianza-laenesima-primera-pelicula-salvadorena

Definición (sin fecha). Ficción. Recuperado de: https://definicion.de/ficcion/

Durán, C.; Marroquín, L.; Olmedo, M. (2012). Caracterización de la producción cinematográfica en El Salvador durante el periodo 2000-2010. Universidad de El Salvador. Recuperado de: http://ri.ues.edu. sv/2641/1/Caracterizaci\%C3\%B3n \%20de\%20la\%20 Producci\%C3\%B3n\%20Cinematogr\%C3\%A1fica\%20 en\%20El\%20Salvador\%20durante \%20el\%20periodo\%202000-2010.pdf

EcuRed (sin fecha). Definición de largometraje. Recuperado de: https://www.ecured.cu /Largometraje

El diario de hoy (3 de enero de 2014). Salas de cine: lo que el tiempo se llevó. Recuperado de: http://www.elsalvador.com/noticias/nacional/121135/salas-de-cinelo-que-el-tiempo-se-llevo-2/

El diario de hoy (19 de octubre de 2015). Malacrianza debuta en El Salvador. Recuperado de: http://www.elsalvador.com/entretenimiento/164367/malacrianzadebuta-en-el-salvador/

El diario de hoy (03 de septiembre de 2017). 5 películas que muestran El Salvador de antaño. Recuperado de: https://historico.elsalvador.com/211430/5-peliculas- 
que-muestran-el-salvador-de-antano.html

Entidad de Gestión de Derechos de los Productores Audiovisuales (2017). Panorama audiovisual iberoamericano 2017. Recuperado de: http://www.egeda.com/ documentos/Panoramalberoamericano2017.pdf

Espinoza Zallas, E., Martínez Solan, C. (2017). Análisis del discurso fílmico a través del modelo dialógico simétrico/asimétrico: vídeo de la danza pascola de losindígenas yoreme de El Fuerte, Sinaloa. Revista de Investigación Académica sin Frontera. Recuperado de: http://revistainvestigacionacademicasinfrontera.com/inicio/wp-content/uploads/2017/07/6.Ana\%CC\%81lisis-del-discurso-fi\%CC\%81/mico_CECILIA-MARTINEZ_EDGAR-ESPINOZA.pdf

IMDB. Malacrianza, ficha técnica. Recuperado de: http://www. imdb.com/title/tt3279818/plotsummary?ref_=tt_ov_pl

Instituto nacional de tecnologías educativas y de formación del profesorado, INTEF (sin fecha). Tema 3: la creación del guion. Recuperado de: http://ficus.pntic. mec.es/ jcof0007/VideoCEP/Tema3/guion.html

Martel, F. (2011). Cultura Mainstream. Cómo nacen los fenómenos de masas. España: Editorial Taurus.

Maza Pérez, M. (2014). Miradas que se cruzan. El espacio geográfico de la frontera entre México y los Estados Unidos en el cine fronterizo contemporáneo. Instituto Tecnológico y de Estudios Superiores de Monterrey. Monterrey, México
Molano, O. (2007). Identidad cultural. Un concepto que evoluciona. Recuperado de: http://www.redalyc.org/ pdf/675/67500705.pdf

Nunca falta alguien que sobre (22 de enero de 2008). Sobreviviendo Guazapa. Recuperado de: http://aniuxita. blogspot.com/2008/01/sobreviviendo-guazapa.html

Núñez, A (2004). Investigación Cualitativa y Análisis del Discurso (Convergencias y encuentros) Recuperado de: http://ajnunezdiscurso.blogspot.com/2013/07/ investigacion-cualitativa-y-analisis.html

Pulecio Mariño, E. (2008) El cine: análisis y estética. Recuperado de: http://www.mincultura.gov.co/areas/cinematografia/publicaciones/Documents/El\%20Cine,\%20 An\%C3\%A1lisis\%20y\%20Est\%C3\%A9tica.pdf

Rincón, O. (2006). Narrativas mediáticas. O como se cuenta la sociedad del entretenimiento. España: Editorial Gedisa

Tribulaciones y asteriscos (27 de enero de 2008). Sobreviviendo Guazapa. Recuperado de: http://rmenjivar. blogspot.com/2008/01/sobreviviendo-guazapa.html

Vallejo Márquez (20 de enero de 2008). Sobreviviendo Guazapa, una película salvadoreña. Recuperado de: http://vallejomarquez.blogspot.com/2008/01/sobreviviendo-guazapa-una-pelcula.html

Zavala, L. (2010). Módulo de cine. Recuperado de: http:// www.laurozavala.info/attachments/Anlisis_Cinematogrfico.pdf 
